\title{
Research
}

\section{Variation in anticoagulation for atrial fibrillation between English clinical commissioning groups:}

\author{
an observational study
}

\begin{abstract}
Background

Despite improvement in anticoagulation for atrial fibrillation (AF), substantial variation in anticoagulation persists between clinical commissioning groups (CCGs) and regions in England.
\end{abstract}

Aim

To identify reasons for variation between English CCGs in anticoagulation for AF.

\section{Design and setting}

A 4-year observational study from 2012/2013

to $2015 / 2016$, of the national Quality and

Outcomes Framework.

\section{Method}

Multiple regression and Pearson's

correlation coefficients were used to analyse anticoagulation for AF in relation to older age Index of Multiple Deprivation, prescription of non-vitamin $\mathrm{K}$ antagonist oral anticoagulants (NOACs), and exception reporting, as well as stroke hospital admission and mortality.

\section{Results}

The proportion of eligible patients in England prescribed anticoagulants for AF without exceptions for clinical complexity or patien dissent increased from $65.1 \%$ in 2012/2013 to $77.9 \%$ in 2015/2016. In 2015, 290920 additional eligible people were anticoagulated in association with use of the $\mathrm{CHA}_{2} \mathrm{DS}_{2} \mathrm{VAS}$ rather than $\mathrm{CHADS}_{2}$ score. From 2012 to 2015 exception reporting almost halved from $20 \%$ to $10.2 \%$. Variation in CCG anticoagulation was not associated with deprivation or NOAC use. There was a strong negative association between exception reporting representing patient complexity and anticoagulation performance, accounting for $57 \%$ of the variation in anticoagulation without exceptions (multiple regression coefficient $=-0.81 ; 95 \%$ confidence intervals $=-0.92$ to $-0.71 ; P<0.001$ l

\section{Conclusion}

Anticoagulation for AF has improved substantially in England in association with considerable increases in the eligible population as a result of decreased exception reporting and the use of the $\mathrm{CHA}_{2} \mathrm{DS}_{2}$ VASc score. There is still substantial room for improvement in most CCGs because, even allowing for exceptions, nine out of 10 CCGs failed to achieve $90 \%$ anticoagulation.

\section{Keywords}

anticoagulation; atrial fibrillation; primary care stroke.

\section{INTRODUCTION}

In 2004, the national Quality and Outcomes Framework (QOF) was introduced with 'pay for performance' to improve quality in primary care delivery, comprising information on performance for 65 clinical indicators in 209 clinical commissioning groups (CCGs) in England in 2015/2016. In the years since its introduction, QOF has been associated with improved overall performance in target conditions, a reduction in the variation between practices and between CCGs in targeted indices, and reduced inequalities in delivery of care. ${ }^{2-4}$ The programme has been considered a cost-effective use of resources and a unique national source of standardised data on major conditions. ${ }^{5}$

Although process measures have substantially improved, it is unclear how much of this is attributable to QOF. Performance in QOF has been associated with little or no reduction in emergency hospital admissions and a failure to demonstrate clear benefits in mortality.,6-9 However, it can be difficult to discern a signal of improvement from broad interventions using observational data drawn from highly variable demographic areas, often in the context of pre-existing trends of improvement. In addition, improvement tends to slow over time as clinical management approaches the optimum. ${ }^{10,11}$ The future of the QOF programme is currently under discussion. ${ }^{12,13}$

Cardiovascular disease has been one

J Robson, MD, FRCGP, reader in primary care research and development; K Homer, MSc, research fellow; $\mathbf{Z}$ Ahmed, MSc, informatics lead, informatician, Centre for Primary Care and Public Health, Queen Mary University of London, London. S Antoniou, MSc, FFRPS, consultant pharmacist,

Barts Health NHS Trust, London.

\section{Address for correspondence}

John Robson, Centre for Primary Care and Public Health, Blizard Institute, Queen Mary University of ondon, 58 Turner Street, London E1 2AB, UK. of the most improved clinical domains in QOF, with major improvements in control of serum cholesterol, blood pressure, and other treatments including anticoagulation. However, it is not clear to what extent these improvements can be attributed to QOF or whether QOF has impacted on outcomes. ${ }^{14-16}$ Studies have found a variable association between QOF performance and reductions in hospital admissions or mortality from cardiovascular disease. ${ }^{17-19}$

Optimal anticoagulation treatment for atrial fibrillation has one of the highest impacts of any medical intervention for a common long-term condition, reducing stroke by $64 \%$ against placebo. ${ }^{20}$ In 2001 the $\mathrm{CHADS}_{2}$ score was introduced to stratify risk in order to inform treatment decisions including those who could avoid anticoagulation. ${ }^{21}$ In 2006 National Institute for Health and Care Excellence (NICE) guidance recommended aspirin and warfarin as options to treat atrial fibrillation and many patients and clinicians opted for the 'easier' medicine. ${ }^{22}$ Anticoagulation or antiplatelet use was introduced as a performance measure in QOF in 2006/2007. However, the combined metric made it impossible to determine rates of anticoagulation separately and reflected the prevailing view that either drug was sufficient. However, contemporaneous surveys showed that $<50 \%$ of people with atrial fibrillation were on an anticoagulant at this time, with most using aspirin monotherapy instead. ${ }^{23,24}$ A Scottish survey

Email: j.robsondamul.ac.uk

Submitted: 23 October 2017; Editor's response: 19 December 2017; final acceptance: 5 February 2018.

\section{CBritish Journal of General Practice}

This is the full-length article lpublished online 3 Jul 2018) of an abridged version published in print. Cite this version as: $\mathbf{B r} \mathbf{J}$ Gen Pract 2018; DOI: https://doi.org/10.3399/bjgp18X697913 


\section{How this fits in}

Anticoagulation in atrial fibrillation (AF) has been suboptimal and variable between clinical commissioning groups (CCGs) in England despite clear national guidance since 2012 recommending anticoagulation rather than aspirin monotherapy. This study shows incremental improvement in anticoagulation since 2012. However, although there was a strong inverse relationship with exception reporting that reflects patient complexity, around $40 \%$ of the variation in eligible patients remained unexplained, indicating opportunities for further improvement in anticoagulation for AF. After allowing for exceptions, nine out of 10 CCGs failed to achieve $90 \%$ anticoagulation.

in 2007 found only $44.4 \%$ of people with atrial fibrillation and a $\mathrm{CHA}_{2} \mathrm{DS}_{2}$ VASc score $\geq 2$ were on anticoagulants at that time, with substantial variation across general practices. ${ }^{25}$ In the US, $40 \%$ of patients with atrial fibrillation in the period 2008-2012 were on aspirin monotherapy. ${ }^{26}$

In the UK, levels of anticoagulation therefore remained lowand largely static until 2012, when the Royal College of Physicians updated its recommendations to advise against the use of aspirin monotherapy in atrial fibrillation, because the evidence did not support optimal stroke reduction. ${ }^{27,28}$ In 2012 QOF introduced anticoagulation for people with $\mathrm{CHADS}_{2}>1$ as a performance measure, allowing exceptions to be reported for clinical contraindications or where patients declined treatment. Since 2012 there has been an increase in the rate of improvement in anticoagulation. In 2014 NICE guidance recommended the use of the $\mathrm{CHA}_{2} \mathrm{DS}_{2}$ VASc score, which added a younger age group of 65-74 years and vascular disease including myocardial infarction to the risk score..$^{29}$ In one study this doubled the proportion of individuals who were eligible for anticoagulation..$^{30}$ In the 2015/2016 QOF results, $77.9 \%$ of eligible patients without exceptions were on anticoagulants. However, this concealed continuing wide variation in anticoagulation between CCGs, ranging from $55 \%$ in Surrey Heath CCG to $86 \%$ in Corby. ${ }^{1}$ Concerns about provider variation in anticoagulation have also been identified in the US and one study reported improved rates of anticoagulation in association with the extent of non-vitamin $\mathrm{K}$ antagonist oral anticoagulants (NOAC) use. ${ }^{31}$

In a decade, clinical guidance and available drugs have transformed the management of atrial fibrillation; NOACs have become the drug of choice and are currently prescribed to more than half of newly anticoagulated patients, with increasing evidence of relative benefits. $^{32}$ In such a rapidly changing evidence base, this study aimed to review national changes in anticoagulation and exception reporting since 2012 and the factors, including the use of NOACs, that might explain continuing variation between CCGs. The study also assessed whether CCG anticoagulation performance influenced hospital admissions for stroke or stroke mortality.

\section{METHOD}

For each CCG in England, data were obtained for the 2012/2013, 2013/2014, and 2014/2015 QOF indicator AF004, which describes the proportion of patients with atrial fibrillation and $\mathrm{CHADS}_{2}>1$ who were currently treated with anticoagulation therapy. Data were also obtained for the 2015/2016 QOF indicator AF007: the percentage of patients with atrial fibrillation and a $\mathrm{CHA}_{2} \mathrm{DS}_{2}$ VASc score $\geq 2$, who were currently treated with anticoagulation therapy.

The proportions of people exception reported from these indicators were also obtained for the relevant QOF indicator. These exceptions comprised a predefined set of indications where treatment was not considered appropriate, including medical contraindications such as previous major bleeding or palliative care, adverse reactions to anticoagulant treatment, or patients who declined anticoagulation.

Mid-year population estimates by age band for 2015 and Census 2011 distributions of ethnic groups for each CCG were available from the Office for National Statistics. ${ }^{33,34}$ The age bands were aggregated into the percentage of patients aged $\geq 65$ years. The mean score by CCG of the English Index of Multiple Deprivation (IMD) 2015 was used to provide a measure of socioeconomic status. ${ }^{35}$

Age-standardised stroke mortality rates for people aged $>75$ years, by CCG in 2012-2014, were available from the Public Health England cardiovascular disease profiles. ${ }^{36}$ For each CCG in 2015/2016, data were extracted from the Sentinel Stroke National Audit Programme for the proportion of people on anticoagulants for atrial fibrillation when they were admitted to hospital with stroke. ${ }^{37}$

The proportion of people on anticoagulants who were prescribed NOACs in 2016 were obtained from the NHS medicines optimisation dashboard and compared with the QOF anticoagulation measures. ${ }^{38}$ 


\section{Statistical analysis}

For the two most recent years, 2014/2015 and 2015/2016, where data were available, Pearson's product-moment correlation was used to assess the unifactorial relationship between the QOF anticoagulation performance indicators, demographic and NOAC variables, and stroke measures. Multiple linear regression was performed to assess the variance of the QOF AF007 performance indicator between CCGs in relation to the proportion of the population aged $\geq 65$ years, the proportion of NOAC prescribing as a proportion of all oral anticoagulant prescribing, and exception reporting in QOF.

Stata (version 14) was used for these analyses.

\section{RESULTS}

From 2012/2013 to 2015/2016, Table 1 shows the number and crude prevalence of atrial fibrillation per 1000 registered patients, and the proportion of these patients who were eligible for anticoagulation in QOF. For those eligible, the number and proportion of patients who were anticoagulated is described. Also shown are the number and proportion of eligible patients who were exception reported.

Over this period, the prevalence of atrial fibrillation increased from 15.2/1000 to 17.1/1000 registered patients. In 2012/2013, of those with a $\mathrm{CHADS}_{2}>1$ without exceptions, 65.1\% (310 580/477 048) were on anticoagulants and after exceptions were excluded $81.4 \%$ (310 580/381 782 were on anticoagulants. Table 1 shows a year on year increase in the proportion of patients on anticoagulants, as well as a decrease in exception reporting. By 2015/2016, the proportion of patients on anticoagulants with a $\mathrm{CHA}_{2} \mathrm{DS}_{2}$ VASc score $\geq 2$ without exceptions had increased to $77.9 \%$ (626 150/803 937) $(S D=3.7$; range $=55.0$ to 86.3$)$. With exceptions excluded, the proportion of patients with a $\mathrm{CHA}_{2} \mathrm{DS}_{2}$ VASc score $\geq 2$ who were on an anticoagulant was $86.7 \%$ (626 150/722 287) (SD = 2.8; range $=79.8 \%$ to $97.4 \%$ ). As expected, variance reduced as the average performance increased with a decrease in the interquartile range from $18 \%$ in 2014 to $15.9 \%$ in 2015 . The proportion of patients who were exception reported decreased from $20 \%$ in 2012 to $10.2 \%$ in 2015 (Table 1).

Even after exceptions were excluded, $30 \%$ of CCGs in 2015/2016 failed to achieve $85 \%$ of eligible patients on anticoagulation and only $10 \%$ of CCGs achieved $90 \%$ or more eligible patients on anticoagulation. The figures $85 \%$ and $90 \%$ are potentially clinically achievable in eligible patients with $\mathrm{CHA}_{2} \mathrm{DS}_{2}$ VASc score $\geq 2$.

\section{CHADS 2 versus $\mathrm{CHA}_{2} \mathrm{DS}_{2}$ VASc}

From 2012 to 2014 the proportion of the total people with atrial fibrillation recorded as eligible for anticoagulation with a $\mathrm{CHADS}_{2}>1$ remained fairly stable at $56.2 \%, 59.6 \%$, and $55.4 \%$ for the 3 years, respectively (Table 1 ). However, in 2015/2016 this eligibility rose to $81.8 \%$, because an additional 290920 people were recorded as eligible, largely as a result of the use of $\mathrm{CHA}_{2} \mathrm{DS}_{2} V A S c \geq 2$, as well as improved recording of this risk score. In other words, an additional $26 \%$ of people with atrial fibrillation were considered eligible for anticoagulant treatment in association with the use of the $\mathrm{CHA}_{2} \mathrm{DS}_{2}$ VASc score.

\section{Demographic and interventional associations}

The variability in the proportion of people on anticoagulants without any exclusion is examined below for the two most recent years for which there are comparative data; all further analyses are of populations without exclusions. Across all CCGs, the mean percentage of the population aged $\geq 65$ years was $17.8 \%$, with a mean deprivation score (IMD 2015) of 21.9 (Table 2). There was a small positive correlation between the percentage of the population aged $\geq 65$ years and the QOF AF007 indicator (proportion of eligible people on anticoagulant); correlation coefficient $=0.20, \quad P=0.003$, explaining 0.04 of the variation $\left(R^{2}\right)$. There was no statistically significant correlation between the QOF AF007 performance indicator and the mean IMD 2015 score among CCGs (information not shown).

\section{NOAC prescribing}

In 2015/2016 there was wide variation in prescribing of NOACs as a proportion of all anticoagulants, ranging from $7 \%$ of all oral anticoagulants in Ipswich and East Suffolk CCG to $73 \%$ in South Kent CCG ( mean $=21.3 \%, 95 \% \mathrm{Cl}=20.0 \%$ to $22.6 \%$ ).

In the unadjusted analysis, there was a small positive correlation between the proportion of NOACs used and the QOF AF007 performance indicator $\left(R^{2}=0.047\right)$. However, this did not remain an independent factor after taking account of age and exception reporting using multiple linear regression (information not shown).

\section{Exception reporting}

Exception reporting for anticoagulation use reduced substantially over time. It averaged $20.0 \%$ in $2012 / 2013,17.0 \%$ in $2013 / 2014$, $12.9 \%$ in $2014 / 2015$, and $10.2 \%$ in $2015 / 2016$ 
Table 2. Characteristics of CCGs in England ( $n=209)^{\text {a }}$

\begin{tabular}{|c|c|c|c|c|c|}
\hline Variable & Mean & SD & 10th centile & Median & 90th centile \\
\hline \multicolumn{6}{|l|}{ Demographics } \\
\hline Total population ONS MYE 2015 & & & 124250 & 230346 & 476845 \\
\hline Population ONS MYE 2015 aged $\geq 65$ years, $\%$ & 17.80 & 4.57 & 11.52 & 18.40 & 23.34 \\
\hline Total population, Census 2011 & & & 117956 & 221345 & 458976 \\
\hline Average IMD 2015 score & 21.91 & 8.35 & 11.17 & 21.28 & 33.18 \\
\hline \multicolumn{6}{|l|}{ QOF performance indicator } \\
\hline AF007 performance indicator 2015/2016, \% & 77.57 & 3.69 & 73.37 & 77.69 & 82.00 \\
\hline Exceptions from anticoagulation therapy $2015 / 2016, \%$ & 10.41 & 3.25 & 6.98 & 10.18 & 13.34 \\
\hline \multicolumn{6}{|l|}{ Stroke measures } \\
\hline Atrial fibrillation before stroke patients on anticoagulants 2015/2016, \% & 44.99 & 10.41 & 31.58 & 45.24 & 57.14 \\
\hline \multicolumn{6}{|l|}{ Prescribing } \\
\hline \% of total anticoagulants prescribed as NOACs in Oct-Dec 2016 & 34.75 & 9.95 & 23.06 & 34.32 & 46.90 \\
\hline
\end{tabular}

(Table 1). In 2015/2016 there was a strong inverse relationship between exception reporting in CCGs: the highest performing CCGs had the lowest exception reporting and vice versa (Table 3). There was a strong negative correlation between the proportion of exceptions and the QOF AF007 performance indicator (correlation coefficient $=-0.74$, $P<0.0001, R^{2}=0.55$ ) (Figure 1). In the multiple linear regression including age and NOAC prescription, exception reporting remained a major factor inversely associated with higher performance $(\beta$ correlation coefficient $=-0.72$, $P<0.001$ ) (Table 4).

\section{Stroke measures}

Across all CCGs, for those people with atrial fibrillation on admission to hospital with a stroke, $45.0 \%$ were already on anticoagulants (Table 2).

There was a small positive correlation between the percentage of patients with atrial fibrillation before stroke admission on anticoagulants and the QOF AF007 performance indicator, explaining 0.04 of the variance $\left(R^{2}\right)$ (correlation coefficient $=0.19$, $P=0.005$ ) (information not shown).

There was no statistically significant correlation between the QOF AF007 2015/2016 anticoagulation performance indicator among CCGs and total stroke admissions in 2015/2016, or the proportion of people with stroke in $2015 / 2016$ who had atrial fibrillation. There was no statistically significant correlation between AF004 2014 and stroke mortality in people aged $>75$ years in 2012-2014 (information not shown).

\section{Regional differences}

By region, a similar inverse relation between exception reporting and anticoagulation performance pattern was present, with the highest exception reporting associated with the lowest regional performance. Table 3 shows the English regional distribution of 2015/2016 QOF AF007 with and without exceptions excluded and the lower than expected anticoagulation in the London region, even allowing for exception reporting.

Figure 2 shows CCG performance by region in 2015/2016 in relation to the mean and $95 \%$ and $99.8 \%$ control limits with and without exceptions. This is also available as an interactive website: https://public. tableau.com/profile/john.robson\#!/vizhome/ AFQoFAnalysis/QOFAFprevalenceovertime.

\section{Table 3. Regional variation in England for exception reporting and anticoagulation performance in $2015 / 2016$}

\begin{tabular}{lccc} 
Region & $\begin{array}{c}\text { Anticoagulated AF007 } \\
\text { without exceptions, \% }\end{array}$ & $\begin{array}{c}\text { Anticoagulated AF007 } \\
\text { with exceptions, \% }\end{array}$ & $\begin{array}{c}\text { Exceptions } \\
\%\end{array}$ \\
South & 78.56 & 87.0 & 9.65 \\
\hline North & 78.10 & 86.9 & 10.07 \\
\hline Midlands and East & 78.08 & 87.1 & 10.31 \\
\hline London & 74.40 & 84.1 & 11.51 \\
\hline
\end{tabular}




\begin{tabular}{|c|c|c|c|c|}
\hline Variable & $\begin{array}{l}\text { Multiple } \\
\text { regression } \\
\text { coefficient }\end{array}$ & $P$-value & $95 \% \mathrm{Cl}$ & $\begin{array}{l}\text { Standardised } \\
\beta \text { coefficient }\end{array}$ \\
\hline Exceptions from anticoagulation therapy, \% & -0.81 & 0.000 & -0.92 to -0.71 & -0.72 \\
\hline Population ONS MYE 2015 aged $\geq 65$ years, $\%$ & 0.10 & 0.007 & 0.03 to 0.18 & 0.13 \\
\hline $\begin{array}{l}\text { Percentage of total anticoagulants } \\
\text { prescribed as NOACs in Oct-Dec } 2016\end{array}$ & 0.03 & 0.109 & -0.01 to 0.06 & 0.08 \\
\hline
\end{tabular}

\section{DISCUSSION}

\section{Summary}

Although there has been substantial improvement in anticoagulation since 2012, variation in anticoagulation between CCGs with and without exception reporting remained notable. This study found that variation was not explained by demographic factors. The delivery of anticoagulation was broadly equitable by age and socioeconomic status with no association with IMD deprivation score and a small positive association between older age and a higher proportion on anticoagulation.

This study highlights the sharp increase in people recorded as eligible for anticoagulation between 2014 and 2015, most likely as a result of changes in eligibility criteria, from using the $\mathrm{CHADS}_{2}$ score in 2014 to the $\mathrm{CHA}_{2} \mathrm{DS}_{2}$ VASc score in 2015. This resulted in an additional $26 \%$ of patients considered as eligible for anticoagulation in 2015.

Although the use of NOACs varied widely between CCGs, their use was not related to the proportion of eligible patients anticoagulated, once age and exception reporting were taken into account. NOAC use has increased substantially in recent years and now accounts for around half of all newly initiated anticoagulants; atrial fibrillation accounts for at least $65 \%$ of this use. $^{39}$ Internationally, NOACs are rapidly becoming the treatment of choice for anticoagulation..$^{40}$ The increase in overall anticoagulation has been shown in previous studies to be a result of switching people previously on aspirin monotherapy to anticoagulation. ${ }^{23}$

No association was found between GP anticoagulation with stroke outcomes or the proportion of people admitted with
Figure 1. Atrial fibrillation QOF AF007. Percentage of exceptions to anticoagulation by $C C G$, in relation to proportion on anticoagulation without exceptions. $A F=$ atrial fibrillation. $C C G=$ clinical commissioning group. QOF = Quality and Outcomes Framework.

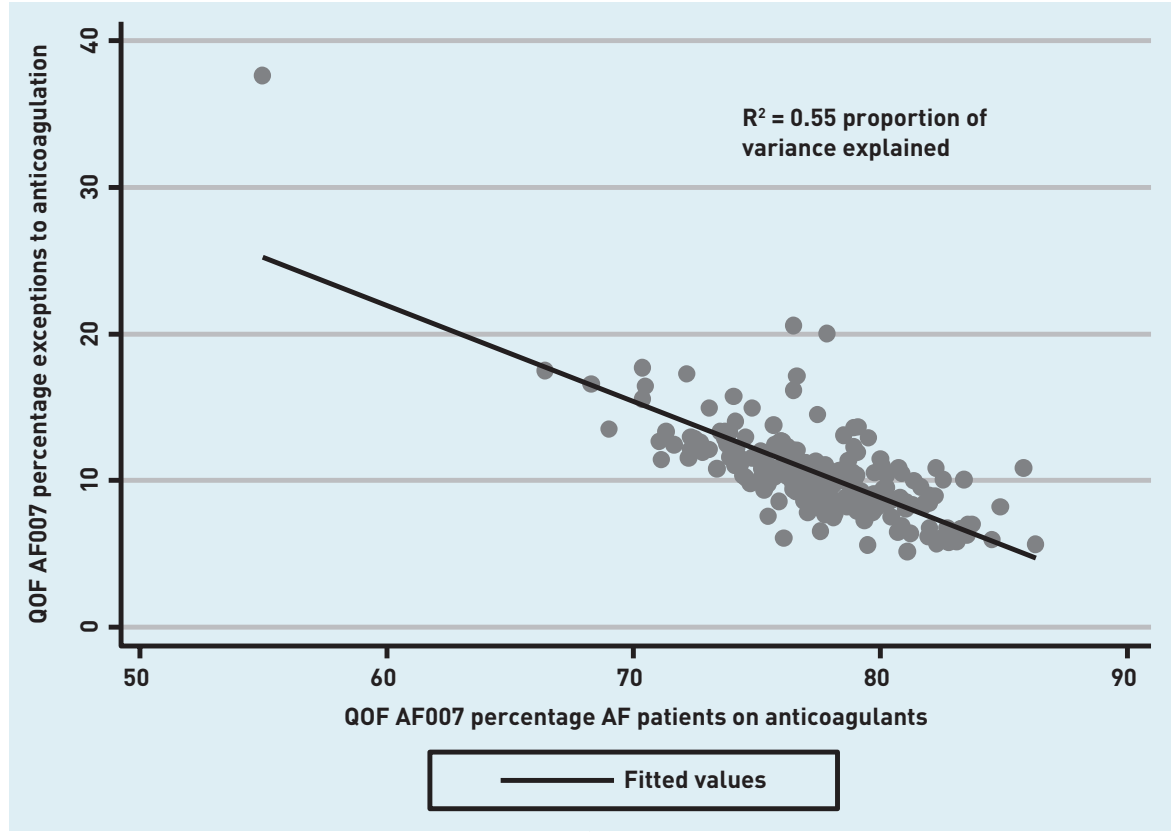


Figure 2. Proportion of people with atrial fibrillation $C H A_{2} D S_{2} V A S c$ score $\geq 2$ on anticoagulation. Distribution in English CCGs by region with and without exceptions 2015/2016. CCG = clinical commissioning group.
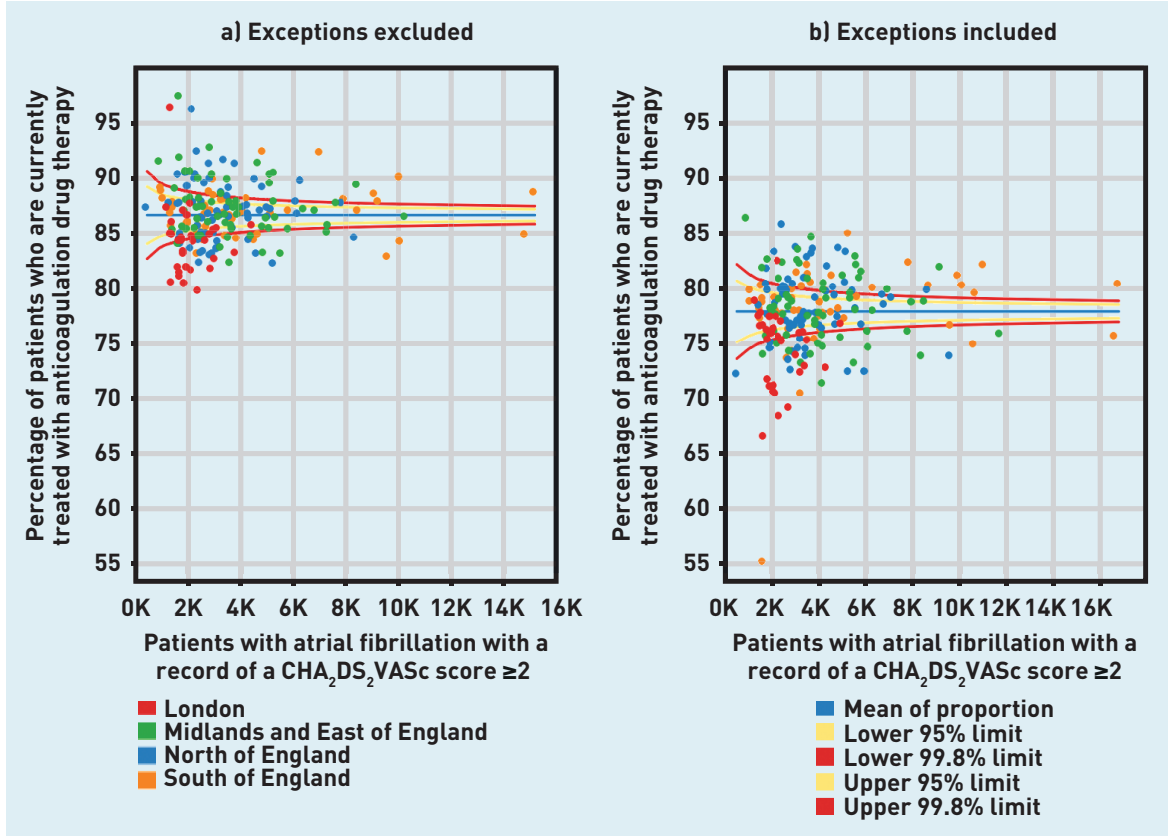

stroke who had atrial fibrillation. The lack of association of GP anticoagulation with stroke is not surprising because $80 \%$ of patients admitted with stroke do not have atrial fibrillation and the extent to which atrial fibrillation is a new or pre-existing diagnosis at hospital admission is unknown. ${ }^{37}$

There was a small positive association between likelihood of anticoagulation in atrial fibrillation in general practice and the likelihood of anticoagulation in patients with atrial fibrillation on admission to hospital with a stroke, which is likely to reflect the increasing rates of GP anticoagulation.

Some CCGs in the London region had lower than expected anticoagulation even after exception reporting. The reasons for this are not known.

\section{Strengths and limitations}

This was an observational and ecological study that describes associations at the CCG level because individual data were not available. As a national study, it is likely to be representative of primary care management of atrial fibrillation.

Available data on NOAC prescribing used in this study relate to indications other than atrial fibrillation and this may obscure the relationship with anticoagulant prescribing for atrial fibrillation. These factors are likely to reduce the strength of the associations found. Ethnic group was not included as a demographic factor as the distribution is highly skewed geographically.

\section{Comparison with existing literature}

Exception reporting was the most notable factor associated with variation in anticoagulation by CCG. The highest rates of anticoagulation occurred in association with the lowest exception reporting. A similar inverse association has been reported for other QOF measures. ${ }^{37}$ Exception rates are known to reflect contraindications to treatment in more complex populations who have more comorbidity and reduced life expectancy. Patient complexity, as indicated by exception reporting, is likely to be a major reason for variability in anticoagulation prescribing before exception reporting is applied, accounting for over half the variation in anticoagulation. ${ }^{41-43}$ However, both the remaining variation after exception reporting, and the substantial reduction in exception reporting over time since 2012, suggest that anticoagulation may be warranted in substantially more patients if more people were considered eligible for anticoagulation.

The Sentinel Stroke National Audit Programme data on stroke ${ }^{37}$ are limited to people admitted to hospital with stroke and do not include out-of-hospital mortality. The individuals admitted are not representative of all patients with atrial fibrillation. In the Sentinel Stroke National Audit Programme, atrial fibrillation was recorded at admission and therefore may include new-onset or previously undiagnosed cases. Thus atrial fibrillation in patients newly admitted with stroke may not be an accurate reflection of longer-term diagnosis or management by GPs. The fact that only $45 \%$ of people with atrial fibrillation admitted to hospital with a stroke were on anticoagulants in comparison 
with $78 \%$ of those patients known to GPs indicates that those admitted were likely to be either newly presenting cases or were not prescribed oral anticoagulants.

Other studies have shown that the most important issue is the $10-20 \%$ of patients with atrial fibrillation who remain on aspirin monotherapy, most of whom are eligible for anticoagulation. Almost all the gain' in anticoagulation has been in this group, rather than those on no anti-thrombotic therapy at all, for whom there may be good reasons for avoiding anticoagulation. ${ }^{23,42}$

\section{Implications for research and practice}

Anticoagulation rates have increased substantially in recent years even though the numbers eligible for anticoagulation have increased due to reduced exception reporting and widening criteria for eligibility. Patient complexity, as indicated by exception reporting, remains an important factor influencing variation in anticoagulation rates. However, substantial variation between CCGs remains unexplained and, even after exception reporting, one in three CCGs failed to achieve levels of $85 \%$ anticoagulation in eligible people with a $\mathrm{CHA}_{2} \mathrm{DS}_{2}$ VASc score $\geq 2$ and only one in 10 CCGs achieved $90 \%$ or more, indicating further room for improvement in anticoagulation.

Additional research at individual patient and practice level might provide more information on the impact of patient complexity on suitability for anticoagulation and the role of other factors influencing variation.

\section{Funding}

This study was independent research supported by the National Institute for Health Research (NIHR) Collaboration for Leadership in Applied Health Research and Care North Thames at Barts Health NHS Trust (NIHR CLAHRC North Thames) in association with Queen Mary University of London. The views expressed in this article are those of the author(s) and not necessarily those of the NHS, the NIHR, or the Department of Health and Social Care.

\section{Ethical approval}

All data were anonymised and managed according to the UK NHS information governance requirements. Ethical approval was not required for the use of anonymised data in this observational study. The study conformed to the STROBE guidance for reporting (https://www.strobe-statement. org/index.php?id=strobe-home).

\section{Provenance}

Freely submitted; externally peer reviewed.

\section{Competing interests}

The authors have declared no competing interests.

\section{Discuss this article}

Contribute and read comments about this article: bjgp.org/letters 


\section{REFERENCES}

1. NHS Digital. Quality and Outcomes Framework (QOF) - 2015-16. 2016. https:// digital.nhs.uk/data-and-information/publications/statistical/quality-andoutcomes-framework-achievement-prevalence-and-exceptions-data/qualityand-outcomes-framework-qof-2015-16 laccessed 11 Jun 2018).

2. Doran T. Kontopantelis E, Reeves D, et al. Setting performance targets in pay for performance programmes: what can we learn from QOF? BMJ 2014; 348: g1595.

3. Harrison MJ, Dusheiko M, Sutton M, et al. Effect of a national primary care pay for performance scheme on emergency hospital admissions for ambulatory care sensitive conditions: controlled longitudinal study. BMJ 2014; 349: g6423.

4. Dusheiko M, Gravelle H, Martin S, Smith PC. Quality of disease management and risk of mortality in English primary care practices. Health Serv Res 2015: 50(5): 1452-1471.

5. Walker S, Mason AR, Claxton K, et al. Value for money and the Quality and Outcomes Framework in primary care in the UK NHS. Br J Gen Pract 2010 DOI: https://doi.org/10.3399/bjgp10X501859.

6. Kontopantelis E, Springate DA, Ashworth M, et al. Investigating the relationship between quality of primary care and premature mortality in England: a spatial whole-population study. BMJ 2015; 350: h904.

7. Reeves D, Springate DA, Ashcroft DM, et al. Can analyses of electronic patient records be independently and externally validated? The effect of statins on the mortality of patients with ischaemic heart disease: a cohort study with nested case-control analysis. BMJ Open 2014; 4(4): e004952.

8. Levene LS, Baker R, Bankart MJ, Khunti K. Association of features of primary health care with coronary heart disease mortality. JAMA 2010; 304(18): 20282034

9. Fleetcroft R, Asaria M, Ali S, Cookson R. Outcomes and inequalities in diabetes from 2004/2005 to 2011/2012: English longitudinal study. Br J Gen Pract 2017; DOI: https://doi.org/10.3399/bjgp16X688381.

10. Ashworth M, Medina J, Morgan M. Effect of social deprivation on blood pressure monitoring and control in England: a survey of data from the quality and outcomes framework. BMJ 2008; 337: a2030.

11. Doran T, Kontopantelis E, Valderas JM, et al. Effect of financial incentives on incentivised and non-incentivised clinical activities: longitudinal analysis of data from the UK Quality and Outcomes Framework. BMJ 2011; 342: d3590.

12. Steel N, Shekelle P. After 12 years, where next for QOF? BMJ 2016; 354: i4103

13. Roland M, Guthrie B. Quality and Outcomes Framework: what have we learnt? BMJ 2016; 354: i4060.

14. Serumaga B, Ross-Degnan D, Avery AJ, et al. Effect of pay for performance on the management and outcomes of hypertension in the United Kingdom: interrupted time series study. BMJ 2011; 342: d108.

15. Karunaratne $K$, Stevens $P$, Irving J, et al. The impact of pay for performance on the control of blood pressure in people with chronic kidney disease stage 3-5. Nephrol Dial Transplant 2013; 28(8): 2107-2116

16. Ashworth M, Lloyd D, Smith RS, et al. Social deprivation and statin prescribing a cross-sectional analysis using data from the new UK general practitioner 'Quality and Outcomes Framework'. J Public Health (Oxf) 2007; 29(1): 40-47.

17. Kiran T, Hutchings A, Dhalla IA, et al. The association between quality of primary care, deprivation and cardiovascular outcomes: a cross-sectional study using data from the UK Quality and Outcomes Framework. J Epidemiol Community Health 2010; 64(10): 927-934

18. Purdy S, Griffin T, Salisbury C, Sharp D. Emergency admissions for coronary heart disease: a cross-sectional study of general practice, population and hospital factors in England. Public Health 2011; 125(1): 46-54

19. Ryan AM, Doran $T$. The effect of improving processes of care on patient outcomes: evidence from the United Kingdom's quality and outcomes framework. Med Care 2012; 50(3): 191-199.

20. Hart RG, Pearce LA, Aguilar MI. Meta-analysis: antithrombotic therapy to prevent stroke in patients who have nonvalvular atrial fibrillation. Ann Intern Med 2007; 146(12): 857-867.

21. Gage BF, Waterman AD, Shannon W, et al. Validation of clinical classification schemes for predicting stroke: results from the National Registry of Atrial Fibrillation. JAMA 2001; 285(22): 2864-2870.

22. National Institute for Health and Care Excellence. Atrial fibrillation: the management of atrial fibrillation. CG36. London: NICE, 2006.

23. Robson J, Dostal I, Mathur R, et al. Improving anticoagulation in atria fibrillation: observational study in three primary care trusts. Br J Gen Pract
2014; DOI: https://doi.org/10.3399/bjgp14X679705.

24. Scowcroft AC, Cowie MR. Atrial fibrillation: improvement in identification and stroke preventive therapy - data from the UK Clinical Practice Research Datalink, 2000--2012. Int J Cardiol 2014; 171(2): 169-173.

25. Dreischulte T, Barnett K, Madhok V, Guthrie B. Use of oral anticoagulants in atrial fibrillation is highly variable and only weakly associated with estimated stroke risk: cross-sectional population database study. Eur J Gen Pract 2014; 20(3): 181-189.

26. Hsu JC, Maddox TM, Kennedy K, et al. Aspirin instead of oral anticoagulant prescription in atrial fibrillation patients at risk for stroke. J Am Coll Cardiol 2016; 67(25): 2913-2923

27. Stott DJ, Dewar RI, Garratt CJ, et al. RCPE UK Consensus Conference on 'Approaching the comprehensive management of atrial fibrillation: evolution or revolution?' J R Coll Physicians Edinb 2012; 42(Suppl 18): 3-4

28. Aguilar MI, Hart R, Pearce LA. Oral anticoagulants versus antiplatelet therapy for preventing stroke in patients with non-valvular atrial fibrillation and no history of stroke or transient ischemic attacks. Cochrane Database Syst Rev 2007; (3): CD006186

29. National Institute for Health and Care Excellence. Atrial fibrillation: management. CG180. London: NICE, 2014.

30. Winkle RA, Mead RH, Engel G, et al. Comparison of CHADS2 and CHA2DS2VASC anticoagulation recommendations: evaluation in a cohort of atrial fibrillation ablation patients. Europace 2014; 16(2): 195-201.

31. Marzec LN, Wang J, Shah ND, et al. Influence of direct oral anticoagulants on rates of oral anticoagulation for atrial fibrillation. J Am Coll Cardiol 2017; 69(20): $2475-2484$

32. Inohara $T$, Xian $Y$, Liang $L$, et al. Association of intracerebral hemorrhage among patients taking non-vitamin $\mathrm{K}$ antagonist vs vitamin $\mathrm{K}$ antagonist oral anticoagulants with in-hospital mortality. JAMA 2018; 319(5): 463-473.

33. Office for National Statistics. Census 2011. Ethnic group. Table population. All usual residents. 2011. http://www.nomisweb.co.uk/census/2011/ks201ew laccessed 28 Feb 2018).

34. Office for National Statistics. Clinical commissioning group mid-year population estimates (national statistics). 2015. https://www.ons.gov.uk/ peoplepopulationandcommunity/populationandmigration/populationestimates/ datasets/clinicalcommissioninggroupmidyearpopulationestimates laccessed 6 Jun 2018).

35. GOV.UK. English indices of deprivation 2015. https://www.gov.uk/government/ statistics/english-indices-of-deprivation-2015 laccessed 6 Jun 2018).

36. Public Health England. Public health profiles. 2018. https://fingertips.phe.org. uk/search/cardiovascular laccessed 19 Jun 2018).

37. Royal College of Physicians. Sentinel Stroke National Audit Programme (SSNAP). Results - Clinical audit. 2017. https://uww.strokeaudit.org/results/ Clinical-audit.aspx (accessed 19 Jun 2018).

38. NHS Business Services Authority. Medicines optimisation dashboard. 2017. https://apps.nhsbsa.nhs.uk/MOD/AtlasCCGMedsOp/atlas.html laccessed 6 Jun 2018).

39. Loo SY, Dell'Aniello S, Huiart L, Renoux C. Trends in the prescription of novel oral anticoagulants in UK primary care. Br J Clin Pharmacol 2017; 83(9): 2096-2106.

40. Gadsboll K, Staerk L, Fosbol EL, et al. Increased use of oral anticoagulants in patients with atrial fibrillation: temporal trends from 2005 to 2015 in Denmark. Eur Heart J 2017; 38(12): 899-906.

41. Kontopantelis E, Springate DA, Ashcroft DM, et al. Associations between exemption and survival outcomes in the UK's primary care pay-forperformance programme: a retrospective cohort study. BMJ Qual Saf2016; 25(9): 657-670.

42. Hess PL, Kim S, Fonarow GC, et al. Absence of oral anticoagulation and subsequent outcomes among outpatients with atrial fibrillation. Am J Med 2017: 130(4): 449-456.

43. Cullen MW, Kim S, Piccini JP Sr, et al. Risks and benefits of anticoagulation in atrial fibrillation: insights from the Outcomes Registry for Better Informed Treatment of Atrial Fibrillation (ORBIT-AF) registry. Circ Cardiovasc Qual Outcomes 2013; 6(4): 461-469 